\title{
EL CONSUMO AUDIOVISUAL DE LOS ESPAÑOLES Y SU POSIBLE USO COMO SOPORTE PUBLICITARIO DE PRODUCTOS Y MARCAS
}

\author{
Noelia Araújo Vila \\ José Antonio Fraiz Brea \\ Universidade de Vigo \\ naraujo@uvigo.es
}

\begin{abstract}
Material original autorizado para su primera publicación en la revista académica REDMARKA. Revista Digital de Marketing Aplicado.
\end{abstract}

https://doi.org/10.17979/redma.2013.01.010.4755

Recibido: 12 Mayo 2013

Aceptado 14 Junio 2013

\section{RESUMEN}

En la sociedad en la que vivimos, los individuos premian el disponer de tiempo libre en el que desconectar de su rutina o trabajo. Como parte de este tiempo de descanso, el sector audiovisual ha ocupado una importante posición, siendo productos audiovisuales como los largometrajes, las series o la música, los que presentan mayor consumo. Los individuos muestran especial interés en ellos, llegando a veces a crear vínculos o signos de empatía con los mismos. Por ello, ante tal interés por parte de los individuos, al resto de sectores se les presenta la oportunidad de darse a conocer a través de dichos productos, posicionando sus marcas en ellos (brand placement). Pero no todos estos productos son adecuados para publicitar cualquier marca, sino que es necesario establecer preferencias. Por ello, en la presente investigación, tras encuestar a 482 espectadores españoles, se exponen resultados vinculados con un producto audiovisual en concreto, las series audiovisuales. Todo ello con el objeto de ayudar a las marcas a elegir en qué tipo de series emplazarse. Palabras clave: serie audiovisual, product placement, brand placement, consumo audiovisual, España. 


\section{ABSTRACT}

AUDIOVISUAL CONSUMPTION OF SPANISH AND ITS POSSIBLE USE AS AN ADVERTISING OF PRODUCTS AND BRANDS

In the society in which we live, the reward individuals have free time in which to unwind from your routine or work. As part of this time off, the audiovisual sector has occupied an important position, and audiovisual products such as feature films, series or music, those with higher consumption. Individuals show special interest in them, sometimes even create links or signs of empathy with them. Therefore, given such an interest on the part of individuals, the other sectors will have an opportunity to get noticed by those products, positioning their brands on them (brand placement). But not all of these products are suitable to advertise any brand, but you need to set preferences. Therefore, in this investigation, after surveying 482 Spanish viewers, presents results associated with a particular audiovisual product, audiovisual series. All this in order to help brands to choose what type of series placed.

Key words: audiovisual series, product placement, brand placement, audiovisual consumption, Spain. 


\section{SECTOR AUDIOVISUAL Y SERIES}

En pleno siglo XXI nos encontramos ante un consumidor con un comportamiento totalmente diferente al de siglos anteriores, fruto de la evolución que la sociedad ha sufrido. Ante el aumento de tiempo libro de dicho individuo, éste se ha visto empujado a buscar actividades placenteras que a su vez contribuyan al desarrollo del propio individuo (Rivas, 2006:72).

Como parte del consumo de este tiempo libre, despuntan sobre las demás actividades ligadas con la cultura, el deporte, el sector audiovisual o el turismo, convirtiéndose en uno de los campos con mayor impacto en la sociedad española.

A su vez, el sector audiovisual es un sector que ha presentado una gran expansión, ampliándose a campos que van más allá del cine, como la televisión, vídeos y todo el mundo multimedia en el que hoy vivimos (Internet, videojuegos o la televisión interactiva entre otros). Se trata de un sector con gran peso en la economía actual, ya no sólo por sí mismo y la creciente demanda que ha despertado y sigue despertando, sino también por su alta y directa vinculación con otros sectores como pueden ser las tecnologías, informática o telecomunicaciones, cuya expansión incentiva el desarrollo de dichos sectores, y viceversa, llegando así a lograr importantes sinergias (Martí y Muñoz, 2001:124).

Centrándonos en este sector, ya sea a través de medios más convencionales como la televisión (con cifras de consumo en España de 240 minutos diarios por persona de media, -Egeda, 2013-) o más actuales y en boga como los medios multimedia (principalmente vía internet en ordenadores personales), podemos hablar de un producto que destaca en todos ellos: las series audiovisuales. 
No se trata de un fenómeno novedoso, ya que sus orígenes los podemos situar en las soap operas ${ }^{1}$ de la década de 1950 dirigidas principalmente a amas de casa (Allen, 1985: 3), ya que haciendo un poco de memoria, décadas de 1970 a 1990, numerosas fueron las series con gran éxito en el momento: Dallas, Colombo, La casa de la pradera, Vacaciones en el mar o Los ángeles de Charlie en la década de 1970, Dinastía, McGiver, El equipo A o El coche fantástico en la década de $1980^{2}$ y Ally McBeal, Buffy la caza vampiros, Los vigilantes de la playa o Padres Forzosos (Step by Step) en $1990^{3}$.

Se vive por tanto en un momento en que las series han alcanzado de nuevo el protagonismo, con la novedad respecto a décadas anteriores del mayor y más fácil acceso a las mismas: descarga vía Internet, DVDs o televisión digital. Ahora el consumidor puede elegir qué series consumir y el momento y modo de consumirlas.

A modo de ejemplo, para poder comprender la repercusión que este producto tiene hoy en día, citaremos un caso relativamente reciente: la emisión del último capítulo de Lost. A pesar de las numerosas series que coexisten en la actualidad, ésta se convirtió en un caso que consiguió atraer a numerosos segmentos de espectadores. El capítulo final, de dos horas y media de duración, fue visionado por 13 millones de espectadores en Estados Unidos, lo que supuso un $23,76 \%$ de share, la mayor audiencia en dos años. Aun así supuso una audiencia más baja de la esperada ante las expectativas generadas -cantidad masiva de anticipación y publicidad previa- (Hollywood Reporter, 20104). Centrándonos en España, donde la cadena de televisión Cuatro apostó por la emisión de tal capítulo en la madrugada del 23 al 24 de mayo, con una hora de retraso respecto a Estados Unidos -necesaria para la traducción-, éste obtuvo récords de audiencia, con una media de share del

\footnotetext{
${ }^{1}$ Del inglés, obras de jabón, ya que se trataba de series destinadas a mujeres que quedaban en casa mientras los maridos iban a trabajar, lo que suponía dos tercios de sus espectadores (Allen, 1985: 3).

2 20minutos.es [consultado el 24/05/2010]

${ }^{3}$ www.cinefania.com [consultado el 24/05/2010]

${ }^{4}$ http://livefeed.hollywoodreporter.com/2010/05/lost-finale-highestrated-episode-in-twoyears.html, [consultado el 25/05/2010]
} 
$31,5 \%$ durante la noche, y en su momento más alto, un 39,6\% -primera parte del último capítulo- (Kantar Media, 2010).

Como se ha dicho, tales cifras son notables a día de hoy, donde la oferta televisiva es variada, pero gran parte de los seguidores de tal serie (losties) optarán por otro tipo de consumo, lo cual se reflejará mayoritariamente en el incremento de descargas vía Internet.

\section{EL BRAND PLACEMENT EN LAS SERIES}

La presencia de marcas comerciales en un formato audiovisual, literario o musical, fenómeno conocido como brand placement, no es una tendencia innovadora del siglo XXI, sino que ha ido creciendo de modo progresivo (Del Pino, 2006:1; Lehu y Bressoud, 2008: 1) hasta convertirse en algo habitual, tanto en cine y televisión (Miles, 2009; Smit, van Reijmersdal y Neijens, 2009) como en otros productos audiovisuales como los videojuegos (Yang y Wang, 2008). La menor eficacia de los cortes publicitarios ante el "cambio de canal" o las restricciones en cuanto a su duración e intervalos han contribuido a ello. Ejemplo de ello es el caso español de prohibición de anuncios en la televisión pública -TVE- (vigente desde inicios de 2010), donde a pesar de que aún es precipitado hacer valoraciones al respecto y los datos son poco significativos, se estima un aumento de audiencia "robada" de televisiones privadas, llegando a cifras del $20 \%$ de share frente al $12 \%$ de cadenas privadas como Tele5 0 Antena3 (Expansión, 2010).

Por tanto, es esperable una reacción por parte de las cadenas televisivas que lleve a influir en los propios guiones de los productos audiovisuales más manejables, las series de ficción, introduciendo en sus contenidos elementos publicitarios. Para ello, la herramienta elegida ha sido la del brand placement, dada su eficacia y notoriedad (Del Pino, 2006: 2), y su introducción en las series audiovisuales viene respaldada por una serie de características que las convierten en un soporte publicitario muy apropiado (Fernández, 2010: 5):

El telespectador empatiza con la serie de ficción. 
Similitud con la vida cotidiana.

Coste por impacto relativamente bajo en comparación con otros medios.

Predisposición por el espectador al visionado de la serie.

Alto poder de los personajes como prescriptores.

Mayor vida del emplazamiento de una marca dada la duración de la serie durante su emisión y futuras reposiciones (o descarga vía Internet).

Las series de ficción son productos con altas audiencias y altos generadores de fidelización.

Datos de estudios de series de ficción emitidas en las dos últimas décadas, respaldan el incremento de esta técnica publicitaria, llegando algunas series a convertirse en referentes con más de 600 marcas emplazadas durante su emisión, como es el caso de Médico de Familia (1995-1999), con 645. Le siguen ejemplos como Periodistas (1998-2002), con 516 emplazamientos de productos, Farmacia de Guardia (1991-1995) con 479 o Lleno por favor (1993) con 232 en tan sólo un año. Aunque cada serie de ficción es diferente -guión, personajes o escenarios-, y se convierte por tanto en más o menos apropiada para publicitar ciertos sectores, se puede hablar de una tendencia que da cabida en estos productos audiovisuales a 9 sectores, ordenados por magnitud de aparición (de mayor a menor): "alimentación", "bebidas", "belleza, higiene y salud", "cultura, enseñanza y medios de comunicación", "automoción", "transportes, viajes y turismo", "objetos personales", "distribución y restauración" y "hogar". En las series que se acaban de citar, marcas vinculadas con la alimentación llegan a tener una presencia del 28,6\%, seguidas de bebidas, 19\%, y belleza e higiene, 13,8\% (Del Pino, 2006: 8). Como ejemplo, está la serie El Barco (Figura 1), destinada a un público joven y adolescente, donde es muy habitual visionar la marca Coca-cola (a pesar de que la trama se centra en el fin del mundo). El sector del transporte y viajes 
muestra una tímida posición, estando en séptimo lugar en cuanto a su promoción emplazada en las series de ficción, representando tan sólo un 4,2\% de los casos.

Figura 1: Brand placement de Coca-cola en El Barco

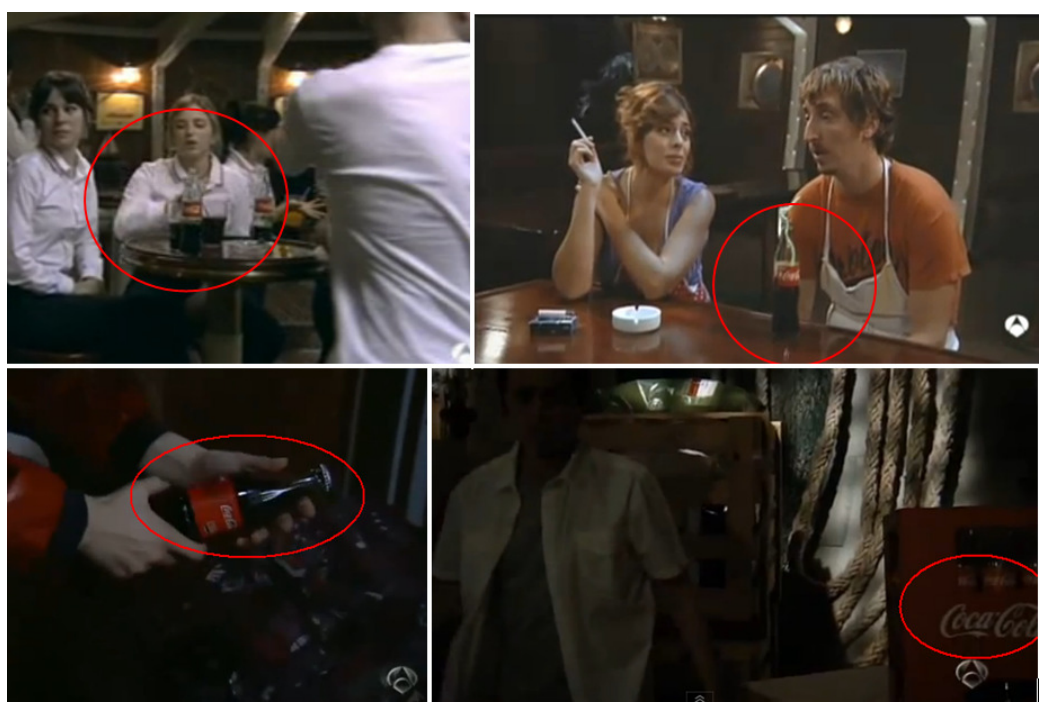

Fuente: capítulos 1, 2, 10 y 12 de la primera temporada de El Barco

Mas esta tendencia ha ido cambiando en la última década, convirtiéndose las series de ficción no sólo en soportes publicitarios de marcas de los sectores citados, sino en potenciales herramientas de promoción de otros sectores, como por ejemplo el turístico (pensemos en el claro posicionamiento de Asturias a través de la serie Doctor Mateo o la aparición de Cantabria de forma indirecta a través del Palacio de la Magdalena en la serie Gran Hotel).

Sea como fuera, es obvio que las series se están convirtiendo en plataformas idóneas para la presentación de productos y marcas, por lo que resulta interesante establecer vínculos entre variables sociodemográficas y consumos de este producto, pudiendo así las empresas saber cuáles series son más adecuadas para posicionar sus marcas. Precisamente estos datos son los que se presentan a continuación. 


\section{3. ¿QUÉ SERIES CONSUME CADA ESPECTADOR?}

Para poder conocer más datos sobre las series consumidas por los españoles, por ejemplo géneros, cómo realizan el consumo o con qué frecuencia, se ha realizado una investigación cuantitativa vía cuestionario (se han encuestado a un total de 482 espectadores españoles). Se debe tener aquí muy presente que las series son el segundo producto audiovisual más consumido en España, sólo superado por el consumo de informativos (la mayoría los consumen prácticamente a diario).

En lo que respecta a los géneros audiovisuales de las series, éstos se pueden clasificar en comedia, drama, ficción, dramedia, serial televisivo y sitcom (o comedia de situación) (Tabla 1). El género favorito por la mayoría es la comedia, con una media próxima a $4(3,98)$ y una moda de 5 . Es decir, a la mayoría le gustan las comedias y al 40,3\% le gustan mucho. El drama, la ficción y las dramedias, presentan unos valores medios próximos a 3, es decir, muestran cierta indiferencia, «ni gustan, ni disgustan». El género peor valorado es el del serial televisivo (las conocidas series de emisión diaria), con una media de 2,54 (entre no me gusta y es indiferente).

Tabla 1. Preferencia de género de las series audiovisuales

\begin{tabular}{|l|l|l|}
\hline Medio & Media & Moda \\
\hline Comedia & 3,98 & 5 \\
\hline Drama & 3,08 & 3 \\
\hline Ficción & 3,18 & 4 \\
\hline Dramedia & 3,10 & 3 \\
\hline Serial televisivo & 2,54 & 1 \\
\hline Sitcom o comedia de situación & 2,73 & 1 \\
\hline Valor mínimo 1; valor máximo 5 & \\
\hline
\end{tabular}

Fuente: elaboración propia

Las preferencias de los espectadores son: 
- En función del género: el consumo es indiferente en los tipos citados, a excepción del drama y la dramedia, preferido por las mujeres.

En función de la edad: la ficción, el serial televisivo y los sitcoms se consumen de modo diferente según la edad del individuo. En el caso de la ficción y el serial televisivo es mejor acogido por el colectivo de edad media (25-44 años), mientras que los sitcoms gustan más al colectivo de menor edad (menores de 25).

Estudios: el drama, la ficción y los sitcom también son consumidos de modo diferente según el nivel de estudios del espectador, siendo la elección del resto de géneros similar en todos los grupos. Cuanto mayor es el nivel de estudios, mayor es la preferencia por el drama, la ficción y los sitcom.

Ocupación: en este caso son 4 los géneros que muestra relación entre la ocupación del individuo y su consumo: el drama, la dramedia, el serial televisivo y el sitcom. El drama y la dramedia es el género preferido de los individuos no activos, mientras que el serial televisivo es el de los estudiantes.

Renta familiar: la elección de los géneros no se ve afectada por la variable renta familiar en la mayoría de los casos, ya que únicamente existe relación de dependencia con el serial televisivo, consumido en mayor medida por los colectivos que ganan menos de 3000 euros mensuales (por unidad familiar).

- № miembros unidad familiar: al igual que el caso anterior, la elección del género de una serie audiovisual es totalmente independiente del número de miembros de la unidad familiar.

El segundo aspecto a analizar, es a través de qué medios o soportes se realiza el consumo de series, pudiendo ser estos la TV/TDT, TV de pago, Vídeo/DVD, ordenador personal vía internet (descargas), página web de cadenas televisivas, PDA o móvil (Figura 2). Esta información resulta útil para las empresas para elegir a través de qué plataformas publicitarse. En este caso, en lo que respecta al género del individuo o el número de miembros de la unidad 
familiar, no se establecen diferencias, consumiendo los diferentes soportes de modo indistinto. Encontramos diferencias en el caso de la edad, los estudios, la ocupación y la renta familiar. La gente joven es la que realiza un mayor consumo vía internet y páginas web, mientras que edades maduras siguen apostando por un consumo vía TV/TDT (mayores de 40 años). En lo que respecta a la renta, como es de esperar, las familias con mayores ingresos realizan un mayor consumo de TV de pago.

Figura 2. Soportes de consumo audiovisual(\%)

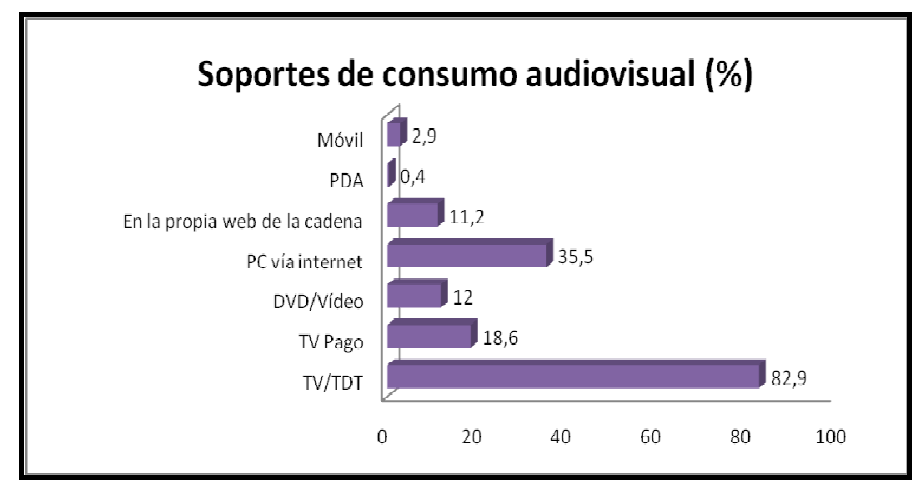

Fuente: elaboración propia

En cuanto a la compañía de visionado de series (Figura 3), se produce también una notable evolución respecto al modelo familiar del siglo pasado. La proliferación de dispositivos de consumo audiovisual a la que se suma el incremento de televisores en cada vivienda, han contribuido a un consumo cada vez más individualizado. La tendencia mayoritaria es un consumo en pareja (45\% de los encuestados), a excepción de los jóvenes entre 14 y 24 años y los estudiantes, que optan por un consumo en solitario. Este consumo más fragmentado resulta muy útil para productos y marcas cuyo público objetivo es la gente joven o adolescentes, ya que se pueden dar a conocer precisamente en las series seguidas por este colectivo, asegurándose un visionado exclusivo por parte de este target. 
Figura 3. Compañía para visionar series (\%)

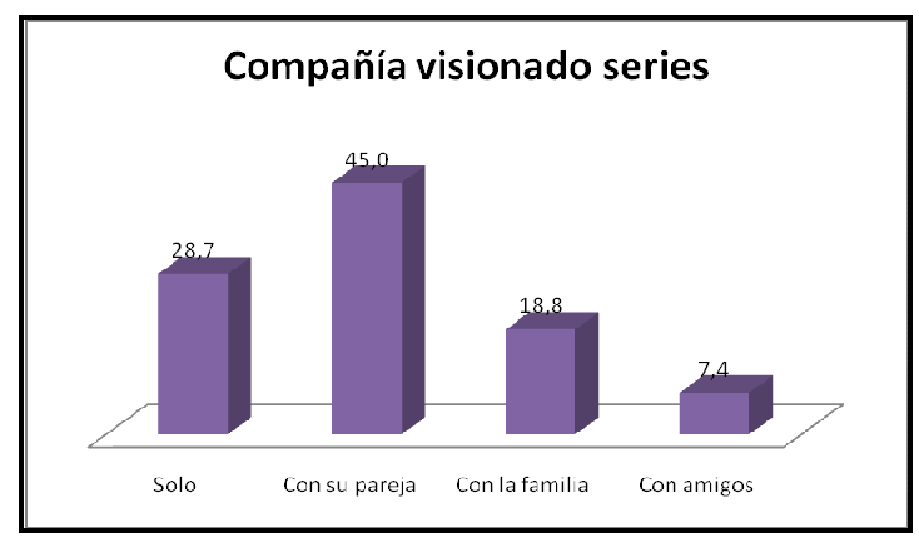

Fuente: elaboración propia

Comentar también que la mayoría de los encuestados visionan más de una serie a la semana, concretamente el 90,9\% visionan 2 o más series, y el $42,4 \%$ consume entre 2 y 5 horas de series (Figura 4 ). Un dato relevante es que de las series visionadas, los espectadores españoles apuestan por la producción nacional, ya que el $48,1 \%$ de la muestra consume 2 o más series nacionales a la semana. Tan sólo el $0,4 \%$ de los encuestados no consumen ninguna serie, y el $21,7 \%$ de los mismos no consumen ninguna serie de procedencia española. Por tanto, las series españolas también se convierten en un buen escaparate de marcas y productos.

Figura 4. Consumo semanal de series

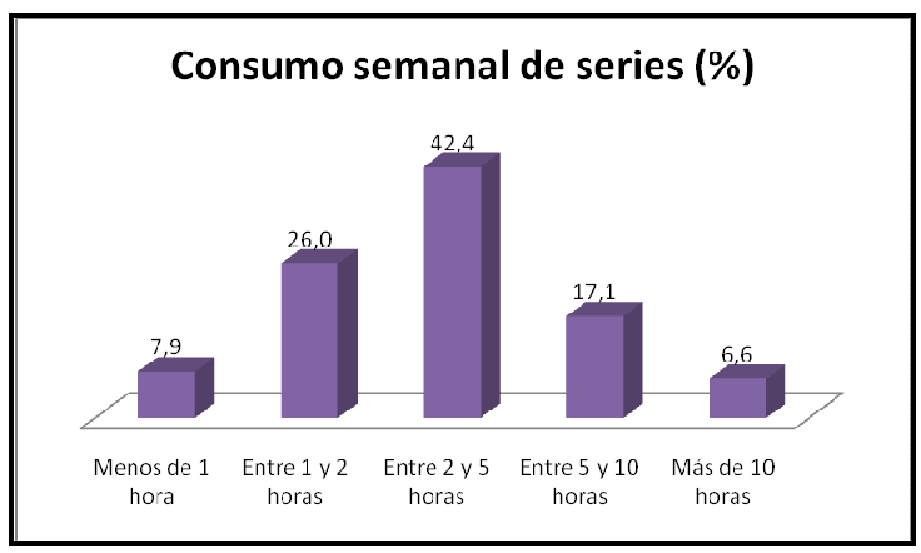


Fuente: elaboración propia

Nos preguntamos aquí, cuáles son entonces las series más visionadas por los españoles. Series como La que se avecina (comedia) o Cuéntame cómo pasó (emitiendo ya su $14^{\text {a }}$ temporada) se encuentran a la cabeza, con audiencias incluso superiores al 20\%. Le siguen El secreto del puente viejo (más de 500 capítulos emitidos), Familia (estrenada en 2013) y El Barco (finalizada en 2013 tras tres temporadas emitidas). Como podemos ver los gustos son variados, aunque la comedia y los dramas de tipo familiar encabezan las preferencias de los españoles (Tabla 1).

Tabla 2: Audiencias de series de televisión españolas más vistas entre enero y febrero de 2013

\begin{tabular}{|l|l|l|}
\hline SERIE & GÉNERO & $\begin{array}{l}\% \text { AUDIENCIA mínimo- } \\
\text { máximo }\end{array}$ \\
\hline $\begin{array}{l}\text { La que se avecina } \\
\text { puéntame cómo }\end{array}$ & Comedia & $20,7-22,4$ \\
\hline $\begin{array}{l}\text { El secreto del Puente } \\
\text { Viejo }\end{array}$ & Telenovela & $15,8-21,1$ \\
\hline Familia & Comedia familiar & $11,3-16,1$ \\
\hline El Barco para & Drama-misterio-acción & $10,2-15,8$ \\
\hline $\begin{array}{l}\text { Amar es } \\
\text { siempre }\end{array}$ & $14,4-15,6$ \\
\hline Gran Reserva & Drama & $13-14,9$ \\
\hline Bandolera & Drama & $10,8-14,7$ \\
\hline Gran Hotel & Drama & $13,7-14,5$ \\
\hline $\begin{array}{l}\text { Luna, el misterio de } \\
\text { Calenda }\end{array}$ & Drama-ficción-misterio & $12,9-13,6$ \\
\hline La Señora & Drama & $10,9-12,9$ \\
\hline Fenómenos & Comedia & $10-11,2$ \\
\hline
\end{tabular}


Fuente: elaboración propia a partir de formulatv.com (2013)

Una vez comentadas las series más visionadas, nos preguntamos a quién recurren los espectadores para asesorarse sobre una serie (lo que influirá en la intención de consumo de la misma) o a quién recurren para comentar las series que siguen (recomendación o no de la serie) (Figura 5). Puesto que estamos en la era de las nuevas tecnologías e Internet, se presuponía que los espectadores acudirían a redes sociales, foros o blogs para informarse sobre las series. Pero la respuesta obtenida no ha sido la esperada, ya que la familia y amigos sigue siendo la fuente de información más consultada (61\% de los encuestados). La publicidad en televisión sigue causando impacto en la población, ya que el $36,6 \%$ de los encuestados se deciden a ver una serie tras verla publicitada en este medio. Aún así, Internet también está ganando campo como medio de información (32,9\% de los encuestados acuden a la red) y finalmente existe un notable porcentaje de los encuestados que ven aleatoriamente series al sentarse delante del televisor y descubrir que en ese momento están emitiendo alguna $(31,2 \%)$ (Figura 5).

En el caso de Internet, esta fuente se encuentra próxima a la familia y amigos en los jóvenes de entre 14 y 24 años, ocupando un segundo puesto para este colectivo. En el caso de los espectadores entre 25 y 44 años, como segunda fuente de información recurren a la propia publicidad en TV y el colectivo de edad más madura (más de 44 años) al visionado de series al azar. En lo que respecta a la formación, los espectadores con estudios más bajos recurren también al azar como segunda opción, mientras que los que poseen estudios universitarios superiores consultan la publicidad en TV e Internet como segunda y tercera vía (prácticamente con la misma frecuencia). En cuanto al sexo, los hombres visionan series al azar como segunda alternativa, mientras que las mujeres acuden a la publicidad en televisión. Mencionar también al colectivo de los estudiantes, que consultan prácticamente con la misma frecuencia que a la familia y amigos, Internet (con porcentajes muy similares). 
Figura 5: Fuentes de información utilizadas para iniciar visionado de series (\%)

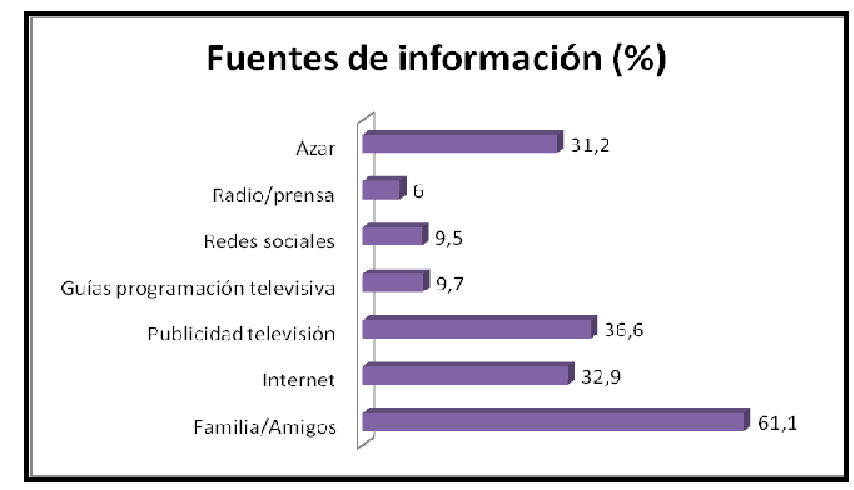

Fuente: elaboración propia

Si nos preguntamos a continuación con quiénes hablan de las series, la respuesta es similar a la anterior: amigos, familia y pareja (Figura 6). Tras un análisis detallado por grupos sociodemográficos, los amigos es el grupo al que se recurre en primer lugar en todos los casos $(67,1 \%)$, seguido de la familia $(51,2 \%)$, a excepción del colectivo de 25 a 44 años, los individuos con formación universitaria, los trabajadores en activo y las unidades familiar con 3 o menos miembros, que prefieren comentar las series con su pareja como segunda alternativa, aunque los valores están muy próximos a los amigos. En lo que respecta a herramientas 2.0 (blogs, webs, foros y redes sociales), su uso es más generalizado entre los más jóvenes (14 a 24 años), los diplomados 0 individuos con FP y los estudiantes, aunque las cifras de consumo son todavía muy bajas en comparación con el trato directo con la familia, amigos y pareja.

Figura 6. Grupos de opinión de series visionadas 


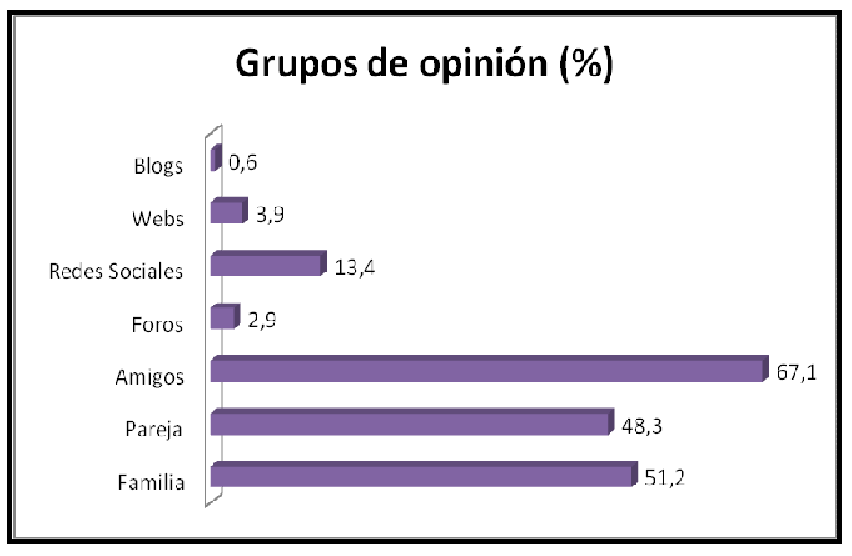

Fuente: elaboración propia

Se concluye por tanto con que las nuevas tecnologías se convierten en una atractiva herramienta promocional para grupos de edades jóvenes. Se pueden aprovechar por tanto páginas de series (blogs, perfiles en redes sociales, foros...) para promocionar productos y marcas destinados a un target joven y adolescente. Para segmentos más maduros éstas no son todavía las herramientas más adecuadas.

\section{CONCLUSIONES}

En el panorama nacional, las series audiovisuales son consideradas el producto audiovisual más consumido, siendo el soporte mayoritario para ello la televisión TDT y el visionado a través de Internet (vía ordenador personal). Las nuevas tecnologías se abren paso como medio de consumo también en este sector, representando actualmente una elevada cuota y pudiendo incrementarse en los próximos años (descargas en Internet o consumo en las propias páginas webs de las cadenas televisivas). Además los espectadores llegan a mostrar ciertas señas de identidad y lealtad hacia las mismas, continuando su visionado cuando éstas son de su agrado y mostrando interés hacia sus personajes y trama. Recordemos aquí que el $48,1 \%$ de espectadores 
encuestados visionan 2 o más series nacionales a la semana, convirtiéndose éstas en una atractiva herramienta de promoción.

A ello se añade el efecto a medio o largo plazo que éstas tienen, en función del número de episodios o de temporadas emitidas. Sea como fuere, se está ante un efecto mucho más duradero que otros productos del sector audiovisual como los largometrajes.

Por ello éstas se convierten en atractivas herramientas publicitarias para otros sectores, los cuales pueden hacer llegar sus productos o marcas a un elevado número de potenciales consumidores, los espectadores. Pero no cualquier serie es adecuada para cualquier producto, sino que es necesario saber en qué serie publicitarse. Por una parte deben ser series con audiencias notables y repercusión nacional y por otra parte series visionadas por el colectivo al que se pretende llegar. Así series como El Barco o El Misterio de Calenda, en las que los elementos de ficción y misterio están presentes, son adecuadas para un público más joven, mientras que series en las que el drama tiene un peso considerable (La Señora o Amar es para siempre) son seguidas en mayor cuantía por el género femenino.

No se debe obviar tampoco la posible promoción a través de herramientas vinculadas a las series, por ejemplo blogs de series o perfiles en Facebook (u otras redes sociales). Aunque se trata de fuentes de información cuyo uso todavía está en crecimiento, los colectivos más jóvenes ya hacen uso de ellas, y los expertos del sector creen que su consumo crecerá considerablemente en un futuro próximo.

En definitiva, lo que es evidente es que el promocionarse a través de una serie es una estrategia mucho más eficaz que por ejemplo el spot publicitario, donde el espectador puede cambiar de canal o no prestar atención. A ello se añade que a través de la serie se puede segmentar el público al que la marca se dirige, además de que el espectador presenta mayor predisposición a lo visionado y vinculado con la misma. 


\section{REFERENCIAS}

Allen, R. C. (1985) Speaking of soap operas. The University of North Caroline Press.

Cinefania (2010). www.cinefania.com [consultado el 24/05/2010]

Del Pino, C. (2006) "El "brand placement" en series españolas. De Farmacia de Guardia a Periodistas: un estudio empírico", Revista Latina de Comunicación Social, № 61: 1-15.

Egeda (2013): Informe Panorama Audiovisual 2012.

Fernández, E. (2010) "Análisis del product placement en la serie Los Hombres de Paco", Prisma Social, №4: 1-6.

Fórmula tv (2013): http://www.formulatv.com/audiencias/ [consultado el $5 / 3 / 2013]$

Hollywood Reporter (2010). http://livefeed.hollywoodreporter.com/2010/05/lostfinale-highestrated-episode-in-two-years.html, [consultado el 25/05/2010]

Kantar Media (2010): audiencia tv.

Lehu, J.M. y Bressoud, E. (2008) "Effectiveness of brand placement: new insights about viewers", Journal of Business Research, Vol. 61 (10): 1083-1090.

Martí, F. P. y Muñoz, C. (2001) "Economía del cine y del sector audiovisual en España", ICE, Economía de la Cultura, № 792: 124-138.

Miles, P. (2009) "The impact of placement type and repetition on attitude", Journal of Advertising, Vol. 38 (3): 21-32.

Rivas, J.B. (2006) "La sociedad del ocio: un reto para los archivos", Códice, red de revistas científicas de América Latina y el Caribe, España y Portugal, Vol. 2, no 002: 71-82.

Smit, E., Van Reijmersdal, E. y Neijens, P. (2009) "Today's practice of brand placement and the industry behind it", International Journal of Advertising, Vol. 28: 761-782. 
Yang, H.L. y Wang, C. S. (2008) "Product placement of computer games in cyberspace", Cyberpsychology \& behavior, vol. 11, №. 4: 399-404. 